\title{
Vascular pattern of milia on dermatoscopy
}

\section{Subrata Malakar ${ }^{1}$, Samipa Samir Mukherjee ${ }^{2}$}

\author{
${ }^{1}$ Department of Dermatology, Rita Skin Foundation, Kolkata, India, ${ }^{2}$ Department of Dermatology, Cutis Academy of \\ Cutaneous Sciences, Bangalore, India
}

Corresponding author: Dr. Samipa Samir Mukherjee, E-mail: drsamipamukherjee@gmail.com

Sir,

Vascular structures in dermoscopy have an important role to play in the categorization of lesions as benign or malignant. Some of the more characteristic findings like crown vessel, comma vessels can help in narrowing down the diagnosis further. Although there has been significant work in dermoscopy for pigmentary disorders, evidence and literature is yet to build with regards to vascular patterns in common dermatological conditions for ease of recognition and diagnosis. We herein describe the vascular pattern that is noted in 2 cases of milia. Similar vascular pattern may occur in basal cell carcinoma that could be misleading and thereby defining the pattern in benign conditions like milia should be considered a necessity.

A 55 year old lady presented with a skin colored asymptomatic lesion over the outer corner of the left eye of almost nine months duration for which no treatment was taken. Clinically she was diagnosed as colloid milium since the papule was firm with a whitish hue and absence of central umbilication. We went on to see the pattern under dermoscopy to confirm the diagnosis by ruling out the differentials. Dermoscopy revealed arborising vessels from the periphery traversing the length of the lesion. White structure less areas were noted interspersed with yellow structureless areas (Fig. 1).

The second case was that of a 30 year old lady who presented with an asymptomatic skin colored lesion over the left nasal ala of one year duration. On clinical evaluation a firm, painless, sessile papulonodule was noted over the left nasal ala and the differentials considered were that of sebaceous hyperplasia and milium. Dermoscopy of the lesion revealed arborising vessel arising from the periphery and crossing a significant length of the lesion along with yellowish white globules (Fig. 2).

Milia most often than not is a clinical diagnosis however can pose a diagnostic challenge in the very young, sun aged face and in the elder individuals. The vascularity of milia and other architectural elements helps in differentiating it from other differentials. In both our cases we found linear arborising blood vessels which were 'in focus' and bright red in colour confirming their epidermal position traversing the length/breadth of the lesion after arising from the periphery. As opposed to blood vessels which are dermal in nature would be pink in colour, less prominent and 'out of focus' due to dispersion of light through the dermal connective tissue [1]. Of note is the fact that the number of these vessels in the lesion may not be very many and thus may be referred to as lonely arborising vessels that may traverse the length of the lesion.

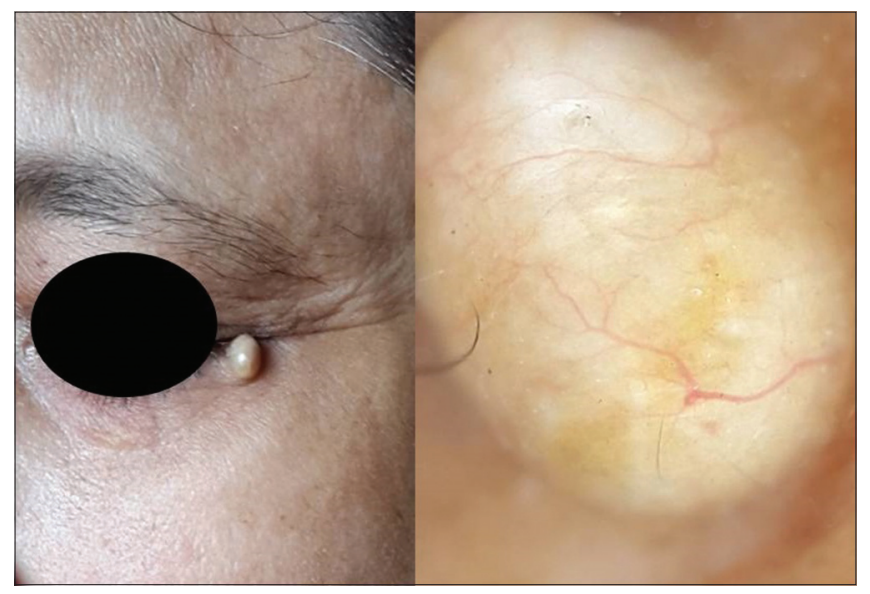

Figure 1: Yellowish to skin colored papulonodule at the outer corner of the eye, dermatoscopy showing yellowish whie structureless areas and arborising vessels arising from periphery traversing the length of lesion. 


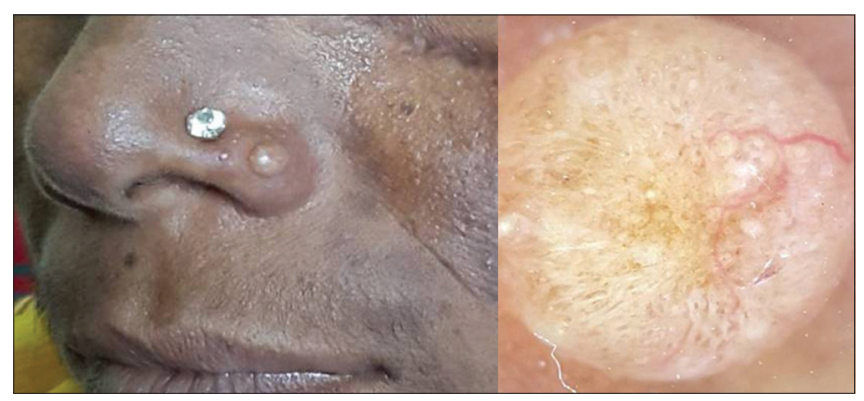

Figure 2: Skin colored papulonodule over the left nasal ala, dermatoscopy showing arborising vessels crossing the length of the lesion and yellowish white milia like cysts structures.

The finding of yellowish white structureless areas to globules on dermoscopy is similar to the milia like cysts that have been described as variously sized white or yellowish structures in seborrhoeic keratoses and congenital melanocytic nevi [2-4].

Superficial vessels are not seen in dermatoscopy of a normal skin, however when present one must think of inflammatory conditions, basal cell carcinoma or topical steroid induced skin atrophy. The vessels in the papillary dermis are visible as dots due to their orientation in a vertical direction and proliferation may be seen in conditions like psoriasis. The sub papillary plexus vessels are oriented horizontally and become visible in inflammatory conditions or when the skin is stretched.in milia there is stretching of the overlying skin leading to apparent upliftment of the subcapillary plexus thereby making these vessels visible of which the pattern has been described.

A milia can be differentiated from a molluscum contagiosum on the absence of crown vessels, mixed flower pattern of vessels and absence of the central orifice [5]. The dermoscopy of sebaceous hyperplasia has been described as a combination of yellowish nodules with crown vessels that are not arborizing [6]. Thus a milium can be differentiated from molluscum contagiosum and sebaceous hyperplasia predominantly on the vascular pattern and partly due to the other associated structural findings. To the best of our knowledge the vascular pattern in a milia has not been reported.

\section{REFERENCES}

1. Zalaudek I, Kreusch J, Giacomel J, Ferrara G, Catricalà C, Argenziano G. How to diagnose non pigmented skin tumours: A review of vascular structures seen with dermoscopy. Part 1. Melanocytic skin tumours. J Am Acad Dermatol. 2010;63:361-4.

2. Argenziano G, Soyer HP, Chimenti S, Talamini R, Corona R, Sera F, et al. Dermoscopy of pigmented skin lesions: results of a consensus meeting via the internet. J Am Acad Dermatol. 2003;48:679-83.

3. Changchien L, Dusza SW, Agero AL, Korzenko AJ, Braun RP, Sachs D, et al. Age- and site-specific variation in the dermoscopic patterns of congenital melanocytic nevi: an aid to accurate classification and assessment of melanocytic nevi. 1. Arch Dermatol. 2007;143:1007-14.

4. Berk DR, Bayliss SJ. Milia: a review and classification. J Am Acad Dermatol. 2008;59:1050-63.

5. Ianhez M, Cestari Sda C, Enokihara MY, Seize MB. Dermoscopic patterns of molluscum contagiosum: a study of 211 lesions confirmed by histopathology. An Bras Dermatol. 2011;86:79-4.

6. Zaballos P, Ara M, Puig S, Malvehy J. Dermoscopy of sebaceous hyperplasia. Arch Dermatol. 2005;141:808.

Copyright by Subrata Malakar, et al. This is an open-access article distributed under the terms of the Creative Commons Attribution License, which permits unrestricted use, distribution, and reproduction in any medium, provided the original author and source are credited.

Source of Support: Nil, Conflict of Interest: None declared. 